\title{
Mortality in the French cohort of nuclear workers
}

\author{
K. Leuraud*, L. Fournier, E. Samson, S. Caër-Lorho and D. Laurier \\ IRSN, Laboratoire d'épidémiologie des rayonnements ionisants, 92262 Fontenay-aux-Roses, France.
}

Received 1 March 2017 / Accepted 20 April 2017

\begin{abstract}
Populations of nuclear workers are particularly relevant to study health effects of protracted exposures to low doses at low dose-rates of ionizing radiation. In France, a cohort of nuclear workers employed by the Commissariat à l'énergie atomique et aux énergies alternatives (CEA), AREVA Nuclear Cycle (AREVA NC), or Électricité de France (EDF), and badge-monitored for external radiation exposure, has been followed-up for several decades. Annual exposure to penetrating photons was reconstructed for each worker. Standardized mortality ratios were calculated using national mortality rates as the reference. Estimates of radiation dose-mortality associations were obtained using linear excess relative risk models. Mortality of 59004 workers was followed-up between 1968 and 2004, for an average of 25 years. The mean cumulative photon $H_{p}(10)$ dose was $18.4 \mathrm{mSv}$ in the whole cohort (median value: $2.1 \mathrm{mSv}$ ) and $25.7 \mathrm{mSv}$ among exposed workers. At the end of the follow-up, workers were 56 years old on average and 6310 workers had died. A strong healthy worker effect was observed. Estimated dose-risk relationships were consistent with those from other worker studies for all solid cancers and leukaemia excluding chronic lymphocytic leukaemia, but remained associated to a large uncertainty. This cohort is the most informative study ever conducted in France among nuclear workers.
\end{abstract}

Keywords: epidemiology / health effect / nuclear worker / exposure, occupational

\section{Introduction}

While health risks induced by high to moderate-dose acute exposure to ionizing radiation (IR) are well characterized (UNSCEAR, 2008; IARC, 2012a), especially by studies on survivors of atomic bombs of Hiroshima and Nagasaki (Douple et al., 2011; Ozasa et al., 2012; Hsu et al., 2013), uncertainty remains regarding the quantification of risks following exposure to protracted low doses of IR, typical of occupational exposures. Populations of nuclear workers are particularly relevant to study potential health effects of low dose and low dose-rate exposures to IR, and cohorts of nuclear workers were implemented worldwide (Vrijheid et al., 2007b). The interest of these studies relies in particular on the availability of individual annual occupational doses monitored in the frame of the radiation protection surveillance.

In France, a large cohort of nuclear workers employed by the Commissariat à l'énergie atomique et aux énergies alternatives (CEA), AREVA Nuclear Cycle (AREVA NC) formerly COmpagnie GEnérale des MAtières nucléaires (COGEMA) and Électricité de France (EDF) has been followed up by the Institute for Radiological Protection and Nuclear Safety (IRSN). Activities of workers from CEA or

\footnotetext{
* Corresponding author: klervi.leuraud@irsn.fr
}

AREVA NC encompass research, nuclear fuel production operations (excluding uranium mining and processing) and fuel reprocessing. Workers from EDF were employed in the 19 French nuclear power plants. One strength of this cohort is the availability, for each worker, of the annual doses of external IR he/she cumulated over his/her occupational life.

This cohort allows to compare the mortality of nuclear workers to that of the French general population and to investigate potential radiation-induced risks of death. In the present analysis, the updated mortality of nuclear workers was examined over the 1968-2004 period, and long-term effects of protracted low level IR exposure were examined, with particular focus on cancer and circulatory diseases mortality.

\section{Material and methods}

This study complies with French ethics recommendations on the use of individual health data and has been approved by the French Data Protection Authority (Comité national de l'informatique et des libertés [CNIL]).

\subsection{Study population}

The French nuclear worker cohort results from the combination of two nuclear worker cohorts implemented in the 1990s, namely the CEA-AREVA NC cohort 
(Telle-Lamberton et al., 2007; Metz-Flamant et al., 2011b) that included 36769 workers and the EDF cohort (Rogel et al., 2005; Laurent et al., 2010) that included 22392 workers. In 2011, these two cohorts were pooled after handling overlapping individuals (Metz-Flamant et al., 2013). The combined cohort includes all workers employed for at least one year by civil CEA or AREVA NC between 1950 and 1994 or by EDF between 1961 and 1994, badge-monitored for radiation exposure and alive on 1 January 1968. Since the previous analysis of this combined cohort (Metz-Flamant et al., 2013), revision of occupational data led to the exclusion of 17 workers. The cohort includes 59004 individuals.

\subsection{Follow-up and mortality data}

The mortality follow-up began at the latest of the three following dates: 1 year after the date of hiring, the date of the first dosimetric monitoring, or 01/01/1968 (as individual medical causes of death are available in France from the national death registry only from 1968, see below). The follow-up ended at the date of death or 12/31/2004 for CEAAREVA NC workers (resp., 12/31/2003 for EDF workers), whichever occurred first. For workers lost to follow-up, it ended at the date of last information (either administrative or dosimetric). Vital statuses were ascertained by linking the cohort with the French National Directory for the Identification of Natural Persons (RNIPP), which is maintained by the National Institute of Statistics and Economic Studies (INSEE) and which gathers information on the vital status of French citizens. Workers who could not be connected to the RNIPP were considered lost to follow-up. Individual causes of death were obtained from the French national registry maintained by the Epidemiology Centre on the medical Causes of Death (CépiDC) of the French National Institute for Medical Research (Inserm). The CépiDC has been registering individual medical causes of death in France since the 01/ $01 / 1968$. The causes of death were coded according to the International Classification of Disease (ICD) in effect at the time of death: ICD8 (WHO, 1968) from 1968 through 1978, ICD9 (WHO, 1977) from 1979 through 1999, and ICD10 (WHO, 2005) from 2000. Since the previous analysis of this combined cohort (Metz-Flamant et al., 2013), further information on causes of death has been collected and integrated in the study.

\subsection{Employment data}

Employing companies provided administrative data and job-related information for each worker. Occupational history at the three employing companies was reconstructed for each worker. As workers could change employers during the followup period, a time-dependent variable was created to define, each year, the company for which the worker had worked the longest from hiring: CEA, AREVA NC, EDF, or other (mainly for subsidiaries of AREVA NC). Duration of employment was defined as a time-dependent variable that increased from the date of hiring until either the date of termination of employment (and remained at that level thereafter), or the end of follow-up if it occurred during active employment. Socioeconomic status was defined for each worker, based on job title at hiring: managers and engineers, administrative employees, skilled and unskilled workers.

\subsection{Radiation exposure data}

Period of exposure ranges from 1950 to 2004. Dose reconstruction and dosimetric practices were described elsewhere for the CEA-AREVA NC cohort (Telle-Lamberton et al., 2007; Metz-Flamant et al., 2011b) and the EDF cohort (Laurent et al., 2010). Annual exposure to external IR (primarily gamma rays) was calculated for each worker from individual doses recorded in the frame of radiological protection surveillance and centralized in companies' dosimetric registries. As part of two international collaborative studies (Thierry-Chef et al., 2007, 2015), data was collected on the type of dosimeter used, on exposure conditions, and on dosimeter response. This data was used to convert individual annual recorded doses to personal penetrating photon dose equivalents in soft tissue at a depth of $10 \mathrm{~mm}\left(H_{p}(10)\right)$ that are expressed in Sievert (Sv) and used in this study.

Some workers may have been exposed to neutrons. However, available information on neutron doses was too sparse and uncertainty associated to dose estimates was too large to include neutron doses in the calculation of external doses (Thierry-Chef et al., 2015). Available information on neutron was used instead to identify workers with substantial exposure to neutrons. A time-dependent flag was thus created. After 1967, this flag labelled the workers as "exposed substantially to neutrons" starting from the first year in which their annual estimated exposure to neutrons exceeded $10 \%$ of their annual total external dose. Prior to 1967, this flag was used starting from the first year in which they had any positive neutron dose because of poor performances of film badges used at that period regarding neutron dosimetry.

Some workers may also have been exposed to internal contamination by various radionuclides (isotopes of uranium, plutonium...), depending on their activities. However, individual measurements of doses from radionuclide intakes are not available for the cohort members since this data has only recently been systematically collected and centralized in France. A companion paper investigated the potential confounding induced by internal contamination in the doserisk analysis in association with external radiation in the cohort, relying on a work-station exposure matrix (Fournier et al., 2015), and potential for internal contamination will not be considered in the present analysis.

\subsection{Statistical analysis}

Mortality in the cohort was compared to that of the French general population by calculating standardized mortality ratios (SMR) using national mortality rates as the reference. A SMR is the ratio of the number of observed deaths in the cohort to the number of "expected" deaths under the hypothesis that mortality rates are the same in the cohort than in the general population. The SMRs were stratified by calendar period in seven categories (1968/1973/1978/1983/1988/1993/1998+), sex, and attained age in 5-year intervals $(<20 / 25 / 30 / \ldots / 75 / 80 /$ $85+$ ). Byar's approximation (Breslow and Day, 1987) was used to estimate $95 \%$ confidence intervals (CI) for the SMRs. 
Results are presented only for causes of death for which at least 10 deaths were observed. For significant excesses of death, further investigations were performed. We calculated SMRs over categories of following professional characteristics: employing company, socioeconomic status, year of hiring, age at hiring, duration of employment, and cumulative dose. We performed a heterogeneity test for SMRs across categories of company and socioeconomic status and a $\chi^{2}(1$ degree of freedom) trend test for SMRs across categories of the other variables (Breslow and Day, 1987).

Poisson regression methods were used to estimate the dose-response relationships between cumulative dose of IR and death from cancer, circulatory diseases, or respiratory diseases. We focused analyses on solid cancer, solid cancer excluding lung cancer, lung cancer, non-Hodgkin lymphoma, multiple myeloma, leukaemia excluding chronic lymphocytic leukaemia (CLL), and myeloid leukaemia; CLL were excluded a priori from the leukaemia grouping as CLL are generally considered to be non-radiogenic (UNSCEAR, 2008). Endpoints for which less than 30 deaths occurred (Hodgkin disease, other sub-types of leukaemia) were not investigated to avoid getting strongly uncertain risk estimations. We used linear excess relative risk (ERR) models as classically used in epidemiology of IR (NRC, 2006). The ERR model can be written as $r(x)=1+\beta x$, where $r(x)$ is the relative rate of death for workers exposed to a cumulative dose $x$ and $\beta$ is the estimate of the ERR per unit dose (ERR/Sv). Models were stratified by calendar period (defined as above), sex, attained age in 5-year intervals, company (CEA, AREVA NC, EDF, other), duration of employment $(<20 \mathrm{y}, \geq 20 \mathrm{y})$, and socioeconomic status, except for leukaemia as preliminary analyses showed no association between socioeconomic status and leukaemia mortality. To allow for a latent period in radiation effect, cumulative dose was lagged by 10 years for the study of solid cancer, circulatory diseases, and respiratory diseases and by 2 years for leukaemia analyses, as is usual in epidemiological studies on radiation induced risks (NRC, 2006). Sensitivity analyses were conducted to investigate the influence of adjustment for the neutron flag.

As the objective of radiation epidemiology is to evaluate if there is an increased risk associated to radiation exposure, one sided $\mathrm{P}$ values and corresponding $90 \% \mathrm{CI}$ are often reported (Muirhead et al., 2009). We also report likelihood-based $90 \%$ CI for the ERRs. All analyses were performed using the EPICURE software (Preston et al., 1993).

\section{Results}

\subsection{Study population}

A total of 59004 workers were followed-up between 1968 and 2004, for an average of 25 years (Tab. 1). They accrued almost 1.5 million person-years. Most of workers were men $(87 \%)$. Most of the cohort members (71\%) were skilled or unskilled workers, $20 \%$ were managers or engineers and $8 \%$ were administrative employees; the socioeconomic status was unknown for less than $1 \%$ of the cohort members. At the end of follow-up, workers were 56 years old on average. Mean duration of employment was 21 years. The mean cumulative dose was $18.4 \mathrm{mSv}$ in the whole cohort; $72 \%$ of the workers had a non-zero cumulative dose, with a mean cumulative dose of $25.7 \mathrm{mSv}$ that reached a maximum of $668.6 \mathrm{mSv}$. Only 597 $(1.0 \%)$ workers cumulated a dose larger than $200 \mathrm{mSv}$, while $35732(60.6 \%)$ workers cumulated doses less than $50 \mathrm{mSv}$. As shown in Figure 1, the distribution of cumulative doses is highly right-skewed with a median value of $2.1 \mathrm{mSv}$ (25th percentile: $0.0 \mathrm{mSv}, 75$ th percentile: $17.0 \mathrm{mSv}$ ). At the end of the follow-up, only $0.2 \%$ of the workers were lost to follow-up and 6310 workers had died. Information on causes of death was available for $97.7 \%$ of the deaths.

\subsection{Mortality analysis}

A strong healthy worker effect was observed in the cohort. Mortality showed a $40 \%$ deficit compared to that of the French general population (all-cause $\mathrm{SMR}=0.60,95 \% \mathrm{CI}$ : 0.59-0.62). Of the 6310 deaths in the cohort, 2552 were due to cancer. The mortality due to solid cancer was $32 \%$ lower in the cohort, compared to the French population (Tab. 2). For most of specific cancer sites, the mortality was lower in the cohort than in the general population, albeit not significantly for malignant tumours of the gallbladder, pancreas, peritoneum, bones, corpus uteri, and kidney (Tab. 2). For malignant tumours of the breast (women only), ovary, brain, and central nervous system, the SMRs were higher than 1.0 but not significantly. Significantly elevated SMRs were observed for pleural cancer, for which mortality was $69 \%$ higher than in the French population, and for skin melanoma which exhibited an excess mortality of $40 \%$. For all tumours of lymphatic and hematopoietic tissues, a slight deficit of mortality was observed (SMR $=0.81,95 \% \mathrm{CI}: 0.70-0.94)$, as well as for specific diseases as leukaemia excluding CLL, non-Hodgkin lymphoma, and multiple myeloma - albeit not significantly for the latter. Conversely, a non-significant excess of mortality was noted for Hodgkin disease. For circulatory, respiratory, or digestive diseases, strong healthy worker effects were observed (Tab. 2).

As significant excesses of death were observed for pleural cancer and skin melanoma, further investigations were performed for these cancer sites. Most of deaths due to pleural cancer $(76.7 \%)$ and skin melanoma (70.5\%) occurred among workers whose principal employer (in terms of duration of employment) was CEA, though SMRs showed no statistically significant heterogeneity across companies. For pleural cancer, the SMRs exhibited no heterogeneity across categories of socioeconomic status $(p=0.43)$, even if a significant excess of mortality was observed for skilled workers. No trend appeared in the SMRs across the categories of age at hiring $(p=0.85)$. By contrast, the SMRs decreased significantly as the year of hiring increased, with higher SMRs observed among workers employed in the early years; the SMRs increased as the duration of employment increased $(p=0.04)$. No trend across categories of cumulative dose could be observed $(p=0.81)$. For malignant skin melanoma, no heterogeneity was observed in the SMRs across categories of socioeconomic status $(p=0.74)$ and the SMRs exhibited no trend across categories of year of hiring $(p=0.65)$, age at hiring $(p=0.32)$, nor cumulative dose $(p=0.25)$. But workers with longer periods of employment showed lower excess of mortality than workers with shorter duration of employment $(p=0.01)$ (Tab. 3). 
Table 1. Characteristics of the French nuclear worker cohort, 1968-2004.

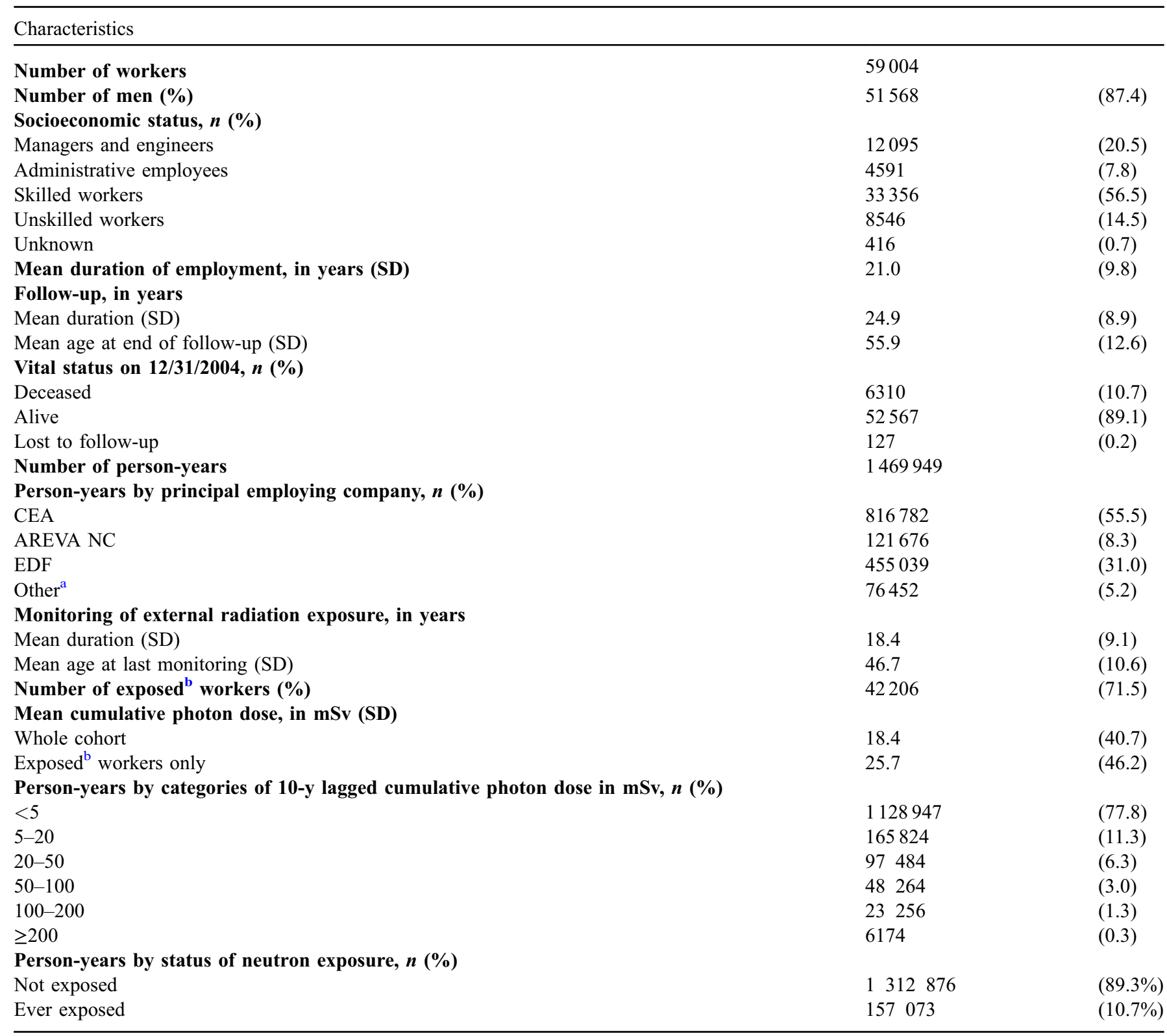

SD: standard deviation.

${ }^{a}$ Mainly for subsidiaries of AREVA NC.

${ }^{\mathrm{b}}$ With at least one positive recorded dose.

\subsection{Analysis of the dose-risk relationship}

Results of the dose-response analysis between cumulative dose and mortality are displayed in Table 4. Positive but imprecise estimates of ERR/Sv were observed for solid cancers. When excluding lung cancer from this grouping, an increase in mortality persisted with a large uncertainty. Models for lymphoma and multiple myeloma could not be fitted. For leukaemia excluding CLL, a positive but not significant ERR/ Sv was found, while for myeloid leukaemia, we observed a high and significant ERR/Sv based on 36 deaths. The ERR/Sv for all circulatory diseases, ischemic diseases or cerebrovas- cular diseases were not significant, albeit positive. For respiratory diseases, a positive but not significant ERR/Sv was also observed, while for chronic obstructive pulmonary disease, the estimated ERR/Sv was not positive.

We performed some sensitivity analyses regarding exposure to neutrons. Adjusting the ERR model on the neutron flag only slightly modified the estimated ERRs for solid cancer (adjusted $\mathrm{ERR} / \mathrm{Sv}=0.37,90 \% \mathrm{CI}$ : $-0.44-1.30$ ), circulatory diseases (adjusted ERR/Sv $=0.33$, 90\%CI: -0.72-1.61), respiratory diseases (adjusted $\mathrm{ERR} / \mathrm{Sv}=1.36, \quad 90 \% \mathrm{CI}$ : -1.05-5.22), and leukaemia excluding CLL (adjusted ERR/ $\mathrm{Sv}=2.22,90 \% \mathrm{CI}:<0-14.13)$. 


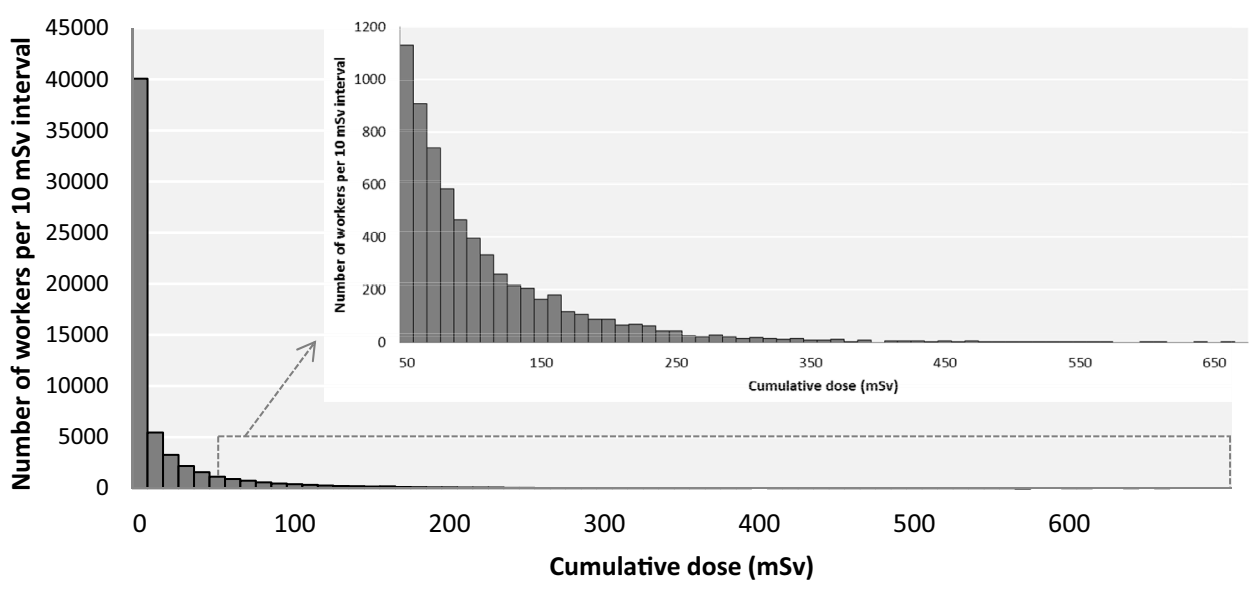

Fig. 1. Distribution of individual cumulative photon doses in the French nuclear worker cohort.

\section{Discussion}

This cohort study is the most informative ever conducted in France among nuclear workers. The merging of the CEAAREVA NC and EDF cohorts into a large national cohort resulted in better statistical precision in radiation risk estimates than in previous analyses (Laurent et al., 2010; Metz-Flamant et al., 2011b, 2012). The low percentage of workers lost to follow-up in this cohort reflects the good quality of this study, partly due to the precision of identifying information contained in the companies' personnel files. The overall mortality was lower than that of the French population. Positive but not significant ERR/Sv were observed for solid cancers, leukaemia excluding CLL, ischemic heart diseases, cerebrovascular diseases, and respiratory diseases.

\subsection{Cancer mortality}

Results confirmed a healthy worker effect in nuclear workers, whose mortality was globally $40 \%$ lower than that of the French general population. A healthy worker effect is often observed in occupational cohorts, especially in nuclear workers (Richardson et al., 2007; Vrijheid et al., 2007b; Hammer et al., 2008; Muirhead et al., 2009; SchubauerBerigan et al., 2015). This well-known effect is generally due to various employment-related components, mainly the healthy hire effect that occurs as healthy people are more likely to enter the workforce than less healthy people and the healthy survivor effect that refers to the process whereby healthy workers remain employed longer than less healthy workers (Howe et al., 1988; Baillargeon, 2001).

We observed a significant excess of death for pleural cancer in the cohort compared to the French population. Similar results have been observed in most studies of nuclear workers (Muirhead et al., 2009; Metz-Flamant et al., 2011a; Merzenich et al., 2014; Schubauer-Berigan et al., 2015). Such an excess was also noted in a cohort of French uranium cycle workers (Samson et al., 2016) that partially overlaps with our cohort (11 deaths by pleural cancer were common to both cohorts); as the authors stated, it was unlikely that the excess could be explained by uranium exposure. The excess of death for pleural cancer in our nuclear worker cohort showed no trend with categories of cumulative dose, but the significant trend in the SMRs associated with duration of employment for pleural cancer suggests that this excess of mortality could be due to some occupational exposure not characterized in this study, albeit this hypothesis cannot be formally confirmed. In France, malignant pleural mesothelioma accounts for about $80 \%$ of the pleural cancers among men (42 over 43 deaths occurred among male workers in our study) and asbestos exposure is its main etiological factor (Montanaro et al., 2003). At the time when nuclear industry expanded in France, in the early 1950's, asbestos was widely used in many industries, with a peak in the 1970's, before its use was prohibited in 1990 (Montanaro et al., 2003; Tossavainen, 2004; Goldberg et al., 2006). Asbestos exposure in the early years of nuclear industry may partly explain the elevated SMR for pleural cancer.

As in previous analyses of the CEA-AREVA NC (MetzFlamant et al., 2011b), an excess of deaths due to malignant skin melanoma was also observed in the cohort. Contrary to cancer of the basal cells of the skin for which exposure to IR is an established risk factor (IARC, 2012a), there is little evidence that IR could induce malignant skin melanoma (UNSCEAR, 2008). Instead, main identified risk factors for skin melanoma are ultraviolet exposure and constitutional factors (including skin reactivity to sunlight and number of moles) (Tucker, 2009). No data on these risks factors are available in the cohort. SMRs for melanoma decreased as duration of employment increased. These results thus do not support the hypothesis of an effect of an unmeasured occupational exposure. Going back in the occupational medical files of the workers who died from malignant skin melanoma could permit retrieving information to explain this excess of mortality.

\subsection{Risk of solid cancer}

A positive but not significant association between mortality from all solid cancers and cumulative dose was observed in this analysis of the French nuclear workers. Although associated to a large uncertainty, the estimated ERR for solid cancer is consistent with the ERR/Sv estimated in the 15-country study $\quad(\mathrm{ERR} / \mathrm{Sv}=0.87, \quad 90 \% \mathrm{CI}$ : $0.16-1.71$, $n=4770$ ) (Cardis et al., 2007). In the third analysis of the 
Table 2. Mortality in the French nuclear worker cohort compared to that of the French population, 1968-2004.

\begin{tabular}{|c|c|c|c|c|}
\hline Cause of death & ICD10 codes & $n$ & SMR & $95 \% \mathrm{CI}$ \\
\hline Solid cancers & C00-C80, C97, except C46.3 & 2356 & 0.68 & $0.65-0.71$ \\
\hline Oesophagus & $\mathrm{C} 15$ & 92 & 0.45 & $0.36-0.55$ \\
\hline Stomach & $\mathrm{C} 16$ & 99 & 0.70 & $0.57-0.86$ \\
\hline Liver & $\mathrm{C} 22$ & 116 & 0.59 & $0.49-0.71$ \\
\hline Gallbladder & $\mathrm{C} 23-\mathrm{C} 24$ & 16 & 0.70 & $0.40-1.13$ \\
\hline Pancreas & $\mathrm{C} 25$ & 139 & 0.94 & $0.79-1.11$ \\
\hline Peritoneum & $\mathrm{C} 26, \mathrm{C} 45.1, \mathrm{C} 48$ & 47 & 0.89 & $0.65-1.18$ \\
\hline Nasal cavity & $\mathrm{C} 30-\mathrm{C} 31$ & 32 & 0.40 & $0.27-0.57$ \\
\hline Skin melanoma & $\mathrm{C} 43$ & 44 & 1.40 & $1.02-1.88$ \\
\hline Breast (women) & $\mathrm{C} 50$ & 70 & 1.05 & $0.82-1.33$ \\
\hline Corpus uteri (women) & C54-C55, C58 & 12 & 0.94 & $0.49-1.65$ \\
\hline Ovary (women) & $\mathrm{C} 56, \mathrm{C} 57.0-\mathrm{C} 57.4, \mathrm{C} 57.8$ & 21 & 1.11 & $0.69-1.70$ \\
\hline Prostate (men) & C61 & 149 & 0.81 & $0.69-0.95$ \\
\hline Bladder & C67, C68 & 56 & 0.51 & $0.39-0.66$ \\
\hline Kidney & C64-C66 & 70 & 0.89 & $0.69-1.12$ \\
\hline Brain et central nervous system & $\mathrm{C} 70-\mathrm{C} 72$ & 84 & 1.03 & $0.82-1.28$ \\
\hline \multicolumn{5}{|c|}{ Tumours of lymphatic and hematopoietic tissue } \\
\hline All & $\mathrm{C} 46.3, \mathrm{C} 81-\mathrm{C} 96$ & 196 & 0.81 & $0.70-0.94$ \\
\hline Respiratory diseases & J00-J99 & 200 & 0.41 & $0.36-0.47$ \\
\hline Chronic obstructive pulmonary disease & $\mathrm{J} 40-\mathrm{J} 44, \mathrm{~J} 47$ & 70 & 0.41 & $0.32-0.52$ \\
\hline Asthma & $\mathrm{J} 45-\mathrm{J} 46$ & 12 & 0.37 & $0.19-0.64$ \\
\hline Digestive diseases & K00-K93 & 270 & 0.37 & $0.32-0.41$ \\
\hline Cirrhosis & K70 & 84 & 0.28 & $0.22-0.34$ \\
\hline
\end{tabular}

ICD10: tenth revision of the International Classification of Diseases; $n$ : observed number of deaths in the cohort; SMR: mortality ratio standardized on calendar period, age, and sex; CI: confidence interval; IP: immuno-proliferative; CLL: chronic lymphocytic leukaemia.

British National Registry of Radiation Workers (NRRW) (Muirhead et al., 2009), the authors reported results for cancer excluding leukaemia, a grouping larger than our solid cancer grouping that excludes lymphoma and multiple myeloma. In the 15-country study, both estimates (for solid cancer and for cancer excluding leukaemia) were comparable (Cardis et al., 2007). The estimated ERR/Sv in the NRRW analysis was 0.28 (90\%CI: 0.02, 0.56, $n=7455$ ), close to our estimate for solid cancer. Analyses were conducted at the IRSN using the most up-to-date Hiroshima and Nagasaki atomic bomb survivors' mortality data (Life Span Study data, LSS) from 1950-2003
(Ozasa et al., 2012), restricted to men, exposed between the ages of 20 and 60 , to derive risk estimates that were comparable to the estimates obtained in the present French nuclear worker combined analyses. Analyses used colon dose in Gray (Gy). The solid cancers ERR/Gy for A-bomb male survivors obtained using an ERR model stratified for attained age, calendar period, and city including modifying effects, was 0.38 (90\% CI: $0.08-0.62)$ for attained age 55 years and age at exposure of 35 years (corresponding respectively to the mean age at end of follow-up and mean age at first exposure in our cohort). Our central estimated ERR/Sv of 0.36 is therefore 
Table 3. Variation of the standardized mortality ratios $\left(\mathrm{SMR}^{\mathrm{a}}\right)$ for pleural cancer and malignant skin melanoma in the French nuclear worker cohort, 1968-2004.

\begin{tabular}{|c|c|c|c|c|c|c|c|c|c|c|}
\hline & \multicolumn{5}{|c|}{ Pleural cancer } & \multicolumn{5}{|c|}{ Skin melanoma } \\
\hline Company & & & & & & & & & & \\
\hline CEA & 33 & 1.74 & $1.20-2.44$ & 0.84 & - & 31 & 1.55 & $1.05-2.19$ & 0.17 & - \\
\hline AREVA NC & 1 & 0.78 & $0.01-4.34$ & & & 3 & 1.38 & $0.28-4.03$ & & \\
\hline $\mathrm{EDF}$ & 7 & 1.87 & $0.75-3.85$ & & & 5 & 0.69 & $0.22-1.61$ & & \\
\hline Managers and engineers & 6 & 1.14 & $0.42-2.48$ & 0.43 & - & 9 & 1.38 & $0.63-2.63$ & 0.74 & - \\
\hline Administrative employees & 2 & 0.91 & $0.10-3.29$ & & & 6 & 2.07 & $0.75-4.49$ & & \\
\hline Skilled workers & 24 & 2.07 & $1.33-3.08$ & & & 19 & 1.23 & $0.74-1.92$ & & \\
\hline Unskilled workers & 11 & 1.77 & $0.88-3.17$ & & & 9 & 1.43 & $0.65-2.71$ & & \\
\hline Unknown & 0 & & & & & 1 & & & & \\
\hline $1970-1979$ & 1 & 0.56 & $0.01-3.10$ & & & 3 & 0.69 & $0.14-2.02$ & & \\
\hline$\geq 1980$ & 1 & 0.46 & $0.01-2.57$ & & & 8 & 1.39 & $0.60-2.74$ & & \\
\hline \multicolumn{11}{|l|}{ Age at hiring (years) } \\
\hline$<25$ & 9 & 1.30 & $0.59-2.47$ & - & 0.85 & 16 & 1.32 & $0.75-2.14$ & - & 0.32 \\
\hline $25-34$ & 22 & 2.05 & $1.28-3.10$ & & & 14 & 1.10 & $0.60-1.85$ & & \\
\hline $35-44$ & 9 & 1.55 & $0.71-2.94$ & & & 12 & 2.39 & $1.23-4.17$ & & \\
\hline$\geq 45$ & 3 & 1.49 & $0.30-4.37$ & & & 2 & 1.29 & $0.15-4.67$ & & \\
\hline \multicolumn{11}{|c|}{ Duration of employment (years) } \\
\hline$<10$ & 3 & 0.71 & $0.14-2.07$ & - & 0.04 & 15 & 2.15 & $1.20-3.55$ & - & 0.01 \\
\hline $10-19$ & 9 & 1.37 & $0.62-2.60$ & & & 16 & 1.77 & $1.01-2.87$ & & \\
\hline$\geq 20$ & 31 & 2.11 & $1.44-3.00$ & & & 13 & 0.85 & $0.45-1.45$ & & \\
\hline \multicolumn{11}{|c|}{ Cumulative photon dose (mSv) } \\
\hline
\end{tabular}

${ }^{a}$ standardized on calendar period, age, and sex. $n$ number of observed deaths in the cohort. CI: confidence interval. $p_{h}$ : bilateral $p$-value of the heterogeneity test, after excluding the unknown category for socioeconomic status. $p_{t}$ : bilateral $p$-value of the $\chi_{(1 \mathrm{df})}^{2}$ Poisson trend test.

consistent with those derived from the LSS, the UK NRWW and the 15-country study. The associated 90\%CIs also appear consistent, even if ours were still larger than those estimated in the LSS and UK NRRW studies (Fig. 2).

\subsection{Risk of leukaemia}

We observed a positive but not significant ERR/Sv for leukaemia excluding CLL. This estimate was higher than the corresponding estimates in the 15-country study (ERR/ $\mathrm{Sv}=1.93,90 \% \mathrm{CI}:<0-7.14, n=196)$ (Cardis et al., 2007), the NRRW study (ERR/Sv $=1.71,90 \% \mathrm{CI}: 0.06-4.29, n=198)$ (Muirhead et al., 2009) or the pooled cohort of nuclear workers from the United States of America (U.S.) (ERR \% per 10 $\mathrm{mSv}=1.70,95 \% \mathrm{CI}:-0.22-4.70, n=369)$ (Schubauer-Berigan et al., 2015). Using a simple linear model and dose to bone marrow to derive a risk estimate for leukaemia excluding CLL with the LSS data (Ozasa et al., 2012), as described above, gave an ERR/Gy=2.63 (90\%CI: 1.50-4.27) (Fig. 2). However, these different studies used different sorts of doses (absorbed dose to the red bone marrow due to penetrating photons for the 15-country study and the LSS, equivalent dose due to external radiation for the NRRW study, equivalent dose due gamma, neutron, and tritium in the pooled cohort of U.S. nuclear workers), which hampers a strict comparison of the numerical coefficients. Moreover, the uncertainty associated to our $\mathrm{ERR} / \mathrm{Sv}$ estimate is large. A significant association with myeloid leukaemia was also found. Other nuclear workers studies showed a higher ERR/Sv for myeloid leukaemia (Richardson and Wing, 2007) or chronic myeloid leukaemia (Muirhead et al., 2009) than for leukaemia excluding CLL. Nevertheless, this result has to be considered with caution as the significant ERR/Sv observed for myeloid leukaemia is our study was mainly due to one death which 
Table 4. Excess relative risk ${ }^{\mathrm{a}}$ of death per Sievert (ERR/Sv) in the French nuclear worker cohort, 1968-2004.

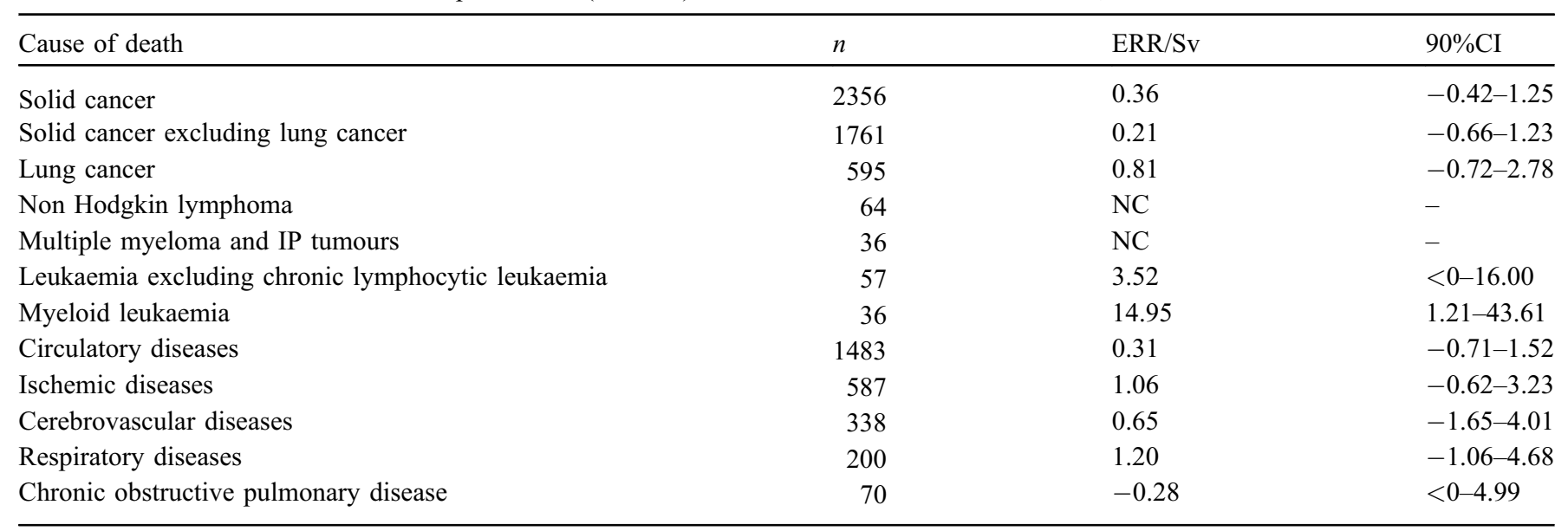

$n$ : observed number of deaths; CI: likelihood-based confidence interval; IP: immuno-proliferative; NC: convergence not achieved; ' $<0$ ' is used when the lower bound of the CI could not be estimated.

${ }^{a}$ Estimated from a linear model of cumulative penetrating photon dose lagged by 10 years (except for leukaemia, lagged by 2 years), stratified on calendar period, age, sex, company, duration of employment, and socioeconomic status (except for leukaemia).

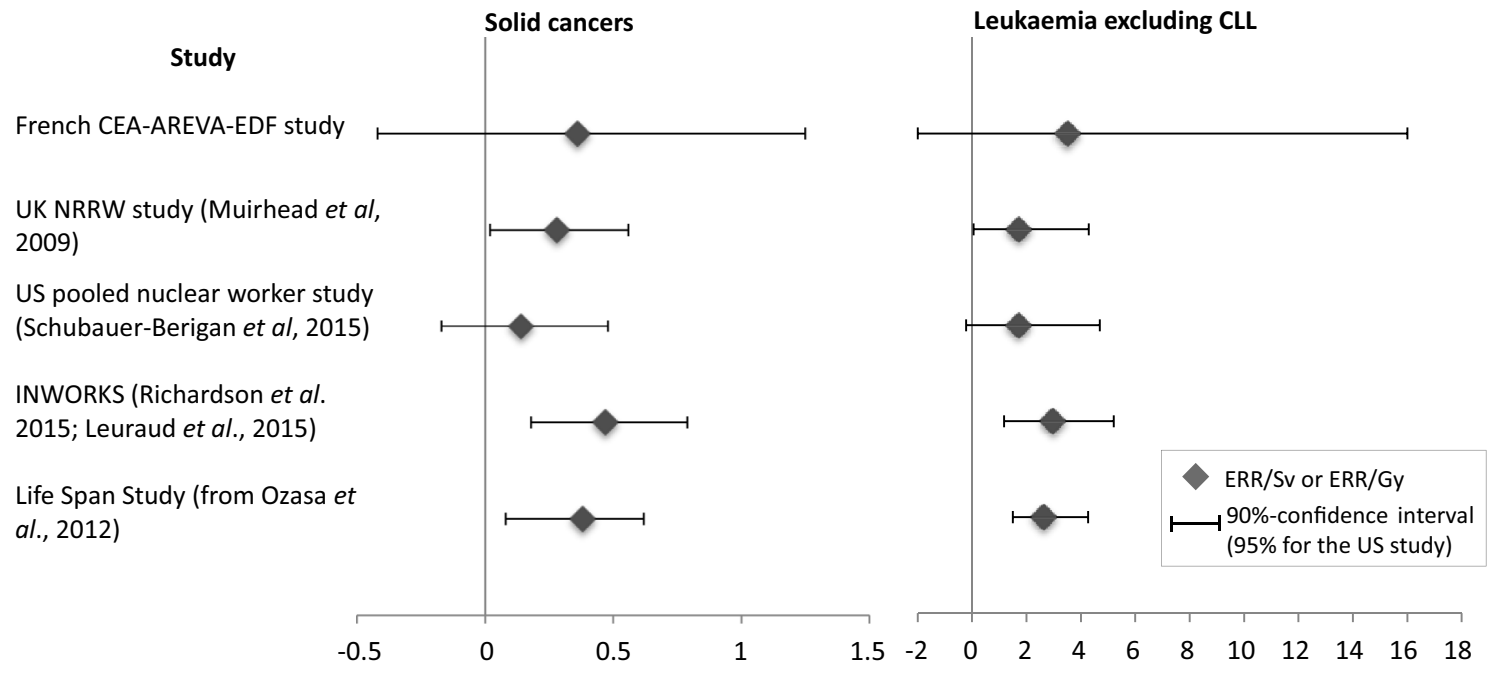

\begin{abstract}
*The ERR are expressed per Sievert (Sv) in the French, UK and US studies and per Gray (Gy) (dose to colon or bone marrow) for INWORKS and the LSS. ** cancers excluding leukaemia for the UK and US studies. The ERR/Gy in the LSS were estimated only for men aged between 20 and 60 at time of bombings; the ERR/Gy for solid cancers includes modifying effect of age at exposure and attained age and is given for men at age at exposure 35 years and at attained age 55 years. The French cohort and part of the UK and US cohorts are included in the INWORKS cohort.
\end{abstract}

Fig. 2. Comparison of the excess relative risks (ERR) per unit dose* estimated for solid cancers** and leukaemia excluding chronic lymphocytic leukaemia (CLL) in the French CEA-AREVA-EDF cohort, the third analysis of the UK National Registry for Radiation Workers (NRRW), the pooled cohort of U.S. nuclear workers, the INWORKS cohort and the Life Span study of Hiroshima and Nagasaki A-bomb survivors.

occurred in the highest dose category. Moreover, some workers may also have been exposed to benzene that is a recognized carcinogenic agent for leukaemia, predominantly acute myelogenous leukaemia (IARC, 2012b); by lack of individual data, the current analyses could not be adjusted on this potential confounder. Implementation of a case-control study nested in the cohort aiming at collecting information on exposures to occupational carcinogens other than IR, as well as on personal habits such as smoking, could be considered.
Such study could contribute to improve the assessment of radiation-induced risk of myeloid leukaemia among nuclear workers (Schubauer-Berigan et al., 2007).

\subsection{Risk of non-cancer diseases}

A positive but not statistically significant association between cumulative dose and mortality from circulatory diseases was observed in this analysis. The central value of the 
estimated ERR/Sv was higher than that in the 15-country study $(\mathrm{ERR} / \mathrm{Sv}=0.09,90 \% \mathrm{CI}:-0.43-0.70, n=8412) \quad$ (Vrijheid et al., 2007a), the NRRW study (ERR/Sv $=0.25,90 \% \mathrm{CI}$ : $-0.03-0.49, n=10$ 509) (Muirhead et al., 2009), the pooled cohort of U.S. nuclear workers (ERR \% per $10 \mathrm{mSv}=0.26$, 95\%CI: $-0.25,0.32$ ) (Schubauer-Berigan et al., 2015) or the LSS (Ozasa et al., 2012), using data restricted to men exposed between the ages of 20 and 60 years $(\mathrm{ERR} / \mathrm{Gy}=0.11,90 \% \mathrm{CI}$ : $0.03-0.19, n=5852)$. However, our result appeared unstable as the ERR/Sv was associated with a large CI and adjustment for duration of employment significantly modified the central estimated value of the ERR/Sv (results not shown). In addition, investigating the risk of circulatory diseases associated with IR in nuclear worker studies will require additional efforts as no information on the major known risk factors for these diseases, such as tobacco use, alcohol consumption, hypertension and high body mass index, is currently available in most of these studies (Metz-Flamant et al., 2009; Little et al., 2012).

The estimated ERR/Sv for respiratory diseases in our study is compatible with the risk estimate in the 15-country study $(\mathrm{ERR} / \mathrm{Sv}=1.16,90 \% \mathrm{CI}:-0.53-3.84, n=792)$ (Vrijheid et al., 2007a) and associated to a large uncertainty. In the LSS, the estimated ERR/Gy among men was lower $(\mathrm{ERR} / \mathrm{Gy}=0.10$, 90\%CI: $-0.03-0.24, n=1879$ ) (Ozasa et al., 2012).

\subsection{Strengths and potential limitations}

A potential limitation may arise from the lack of causes of death before 1968 in France. Among workers who complied with the inclusion criteria of this study, 157 workers from CEA were not included in the cohort as they died before 1968. This problem was discussed by Metz-Flamant et al. (2011b) who estimated the SMR for all causes of death including those workers on the 1946-2004 period and showed that it was similar to the SMR for the 1968-2004 period in the CEAAREVA NC cohort. Moreover, this cohort only includes workers hired by the three employers, CEA, AREVA NC or EDF. In France, there is also a population of workers from contracting companies who operate in the nuclear industry and who are badge-monitored for radiation exposure. This population was not included in the national nuclear worker cohort due to the difficulty of ensuring a high level quality of follow-up (as is the case in the CEA-AREVA NC-EDF cohort). Information in administrative archives of contracting companies is indeed often incomplete, mainly for the years before 1980, making it difficult to reconstitute properly job and dosimetric histories and to link workers' identifiers with national population registries to ascertain vital statuses and causes of death. This difficulty was illustrated by a study of cancer mortality among nuclear contract workers in France (Guérin et al., 2009). Among the 11577 identified individuals, $4615(40 \%)$ were excluded of the cancer mortality analyses because of uninformative identifiers (name, date of birth...). The results showed a healthy worker effect (all causes $\mathrm{SMR}=0.54,95 \% \mathrm{CI}: 0.47-0.61)$ of the same order of magnitude than in our study. They also found a statistically significant ERR for all cancers $(\mathrm{ERR} / 100 \mathrm{mSv}=0.56,95 \% \mathrm{CI}$ : 0.01-1.6) that appears to be very high but that must be interpreted with caution given the very low number of deaths due to cancer $(n=90)$ and the probable incompleteness in the dosimetry reconstruction.
The workers included in our study were monitored for external exposure to IR. As data on neutron doses were sparse and subject to uncertainty, we considered only exposure due to penetrating photons in the risk analysis. Workers with a substantial neutron dose were flagged and sensitivity analyses showed that adjusting the ERR model for the neutron flag did not affect the ERR/Sv. A potential bias due to omitting neutron dose in the cumulative dose, if any, may thus be low.

Some workers had also internal contamination from inhaled particles of uranium or plutonium (Canu et al., 2010). Currently, in vivo and bioassay monitoring results for internal deposition of radionuclides are not available for all cohort members. To address that limit, a previous study on the cohort assessed the potential bias in the estimation of the doserisk relationship due to omitting information on internal contamination (Fournier et al., 2015). Workers at risk of potential internal contamination were identified based on a workstation-exposure matrix. The results suggested that in this cohort, neglecting information on internal dosimetry while studying the association between external dose and cancer mortality did not generate a substantial bias.

Adjustment for socioeconomic status was used to partly take account of the lifestyles of workers, such as smoking habits. Adjustment for determinants of cigarette smoking, such as sex, age, birth cohort, and socioeconomic status, reduces the potential for large systematic differences in smoking prevalence between occupational exposure groups (Axelson, 1989). To further address this concern, we estimated the ERR/Sv for solid cancers excluding lung cancer. Even if the central estimate was lower than the central estimate for all solid cancers, both $90 \% \mathrm{CI}$ were consistent. Moreover, the lack of association between the cumulative photon dose and the risk of chronic obstructive pulmonary disease, which is known to be strongly associated to smoking, is in favour of a weak confounding by smoking (Richardson et al., 2014).

This is the largest study of French nuclear workers conducted so far in France. Despite a long follow-up (19682004), this combined cohort, which is characterised by a particularly low mean cumulative exposure to IR $(18 \mathrm{mSv})$, presents a lack of statistical power to precisely estimate risks associated to low doses of IR. This is mainly due to the young age of workers at last observation (56 years), while most of deaths due to cancer occur later in life. Extending the followup of this cohort in the future is thus crucial.

Another way to reach better power in epidemiological studies is to conduct combined analyses of several studies to increase the size of the population. The French cohort contributed to a large international combined analysis of nuclear workers coordinated by the International Agency for Cancer Research (the INWORKS project) (Hamra et al., 2016; Laurier et al., 2017). A pooled cohort of 308297 workers from France, the United Kingdom, and the U.S., was assembled and an extensive work on the dosimetry was performed to ensure homogeneity in the calculation of doses due to penetrating photons among the three countries (Thierry-Chef et al., 2015). Radiation induced risks of leukaemia and solid cancers could be estimated with a good level of precision. A significant doserisk relationship was observed between mortality by leukaemia excluding CLL and red bone marrow dose $(\mathrm{ERR} / \mathrm{Gy}=2.96$, 90\% CI: 1.17-5.21) (Leuraud et al., 2015) and also between mortality by solid cancer and colon dose (ERR/Gy $=0.47,90 \%$ 
CI: 0.18-0.79) (Richardson et al., 2015). The results showed no heterogeneity in the country specific risk estimates. Figure 2 summarizes the results of the dose-risk analyses for solid cancer and for leukaemia in INWORKS (Richardson et al., 2015; Leuraud et al., 2015), the French nuclear worker cohort, the NRRW study (Muirhead et al., 2009), the pooled cohort of U.S. nuclear workers (Schubauer-Berigan et al., 2015), and in the LSS (analyses restricted to men, exposed between the ages of 20 and 60). It displays the estimated ERR per unit dose as published in the different studies: the ERR are thus expressed per $\mathrm{Sv}$ in the French, UK and U.S. studies and per Gy for INWORKS and the LSS. Figure 2 reflects how, despite large uncertainties in the French study, central estimates of the ERR are in good agreement across the different studies.

\section{Conclusion}

Cohorts of nuclear workers are particularly relevant to study potential health risks induced by exposure to low doses of IR delivered at low dose rates, as they permit direct assessment of dose-risk relationships and thus prevent making hypotheses when extrapolating coefficients derived in a frame of acute high dose exposure, as is the case in the LSS. The study of the French nuclear worker cohort shows that workers are globally in better health than the general population. The estimated risks following occupational exposure to IR remain associated to large uncertainties. Further analyses based on a longer follow-up will allow improving the precision of risk estimates. Other ways to improve the assessment of radiation related-risks include a better characterization of other sources of occupational exposures and personal risk factors for the diseases of interest and the continuation of international collaborations.

Acknowledgments. This report makes use of data obtained from the Radiation Effects Research Foundation (RERF), Hiroshima and Nagasaki, Japan. RERF is a private, non-profit foundation funded by the Japanese Ministry of Health, Labour and Welfare (MHLW) and the U.S. Department of Energy (DOE), the latter in part through DOE Award DE-HS0000031 to the National Academy of Sciences. The conclusions in this report are those of the authors and do not necessarily reflect the scientific judgment of RERF or its funding agencies.

The construction of the French cohort was realized by the IRSN, with partial funding from AREVA and EDF. This funding had no impact on the study design, analyses, or interpretation of results. IRSN thanks all persons from CEA, AREVA, and EDF who cooperated in the elaboration of the French cohort by providing access to sources of administrative and dosimetric data for this study.

\section{References}

Axelson O. 1989. Confounding from smoking in occupational epidemiology. Br. J. Ind. Med. 46: 505-507.

Baillargeon J. 2001. Characteristics of the healthy worker effect. Occup. Med. Art Rev. 16: 359-366.

Breslow NE, Day NE. 1987. Statistical methods in cancer research. IARC Scientific Publications No. 82. Lyon: IARC Press.
Canu IG, Cardis E, Metz-Flamant C, Caër-Lorho S, Auriol B, Wild P, Laurier D, Tirmarche M. 2010. French cohort of the uranium processing workers: mortality pattern after 30-year follow-up. Int. Arch. Occup. Environ. Health 83: 301-308.

Cardis E, Vrijheid M, Blettner M, Gilbert E, Hakama M, Hill C, Howe G, Kaldor J, Muirhead CR, Schubauer-Berigan M, Yoshimura T, Bermann F, Cowper G, Fix J, Hacker C, Heinmiller B, Marshall M, Thierry-Chef I, Utterback D, Ahn Y-O, Amoros E, Ashmore P, Auvinen A, Bae J-M, Bernar J, Biau A, Combalot E, Deboodt P, Diez Sacristan A, Eklöf M, Engels H, Engholm G, Gulis G, Habib RR, Holan K, Hyvonen H, Kerekes A, Kurtinaitis J, Malker H, Martuzzi M, Mastauskas A, Monnet A, Moser M, Pearce MS, Richardson DB, Rodriguez-Artalejo F, Rogel A, Tardy H, TelleLamberton M, Turai I, Usel M, Veress K. 2007. The 15-country collaborative study of cancer risk among radiation workers in the nuclear industry: estimates of radiation-related cancer risks. Radiat. Res. 167: 396-416.

Douple EB, Mabuchi K, Cullings HM, Preston DL, Kodama K, Shimizu Y, Fujiwara S, Shore RE. 2011. Long-term radiationrelated health effects in a unique human population: lessons learned from the atomic bomb survivors of Hiroshima and Nagasaki. Disaster Med. Public Health Prep. 5: S122- S133.

Fournier L, Laurent O, Samson E, Caër-Lorho S, Laroche P, Le Guen B, Laurier D, Leuraud K. 2015. External radiation dose and cancer mortality among French nuclear workers: considering potential confounding by internal radiation exposure. Int. Arch. Occup. Environ. Health 89: 1183-1191.

Goldberg M, Imbernon E, Rolland P, Gilg Soit Ilg A, Saves M, de Quillacq A, Frenay C, Chamming's S, Arveux P, Boutin C, Launoy G, Pairon JC, Astoul P, Galateau-Sallé F, Brochard P. 2006. The French national mesothelioma surveillance program. Occup. Environ. Med. 63: 390-395.

Guérin S, Richard G, Biau A, Lebre S, Crescini D, Haddy N, Guldner L, Paoletti C, Hill C, De Vathaire F. 2009. Cancer mortality among French nuclear contract workers. Am. J. Ind. Med. 52: 916-925.

Hammer GP, Fehringer F, Seitz G, Zeeb H, Dulon M, Langner I, Blettner M. 2008. Exposure and mortality in a cohort of German nuclear power workers. Radiat. Environ. Biophys. 47: 95-99.

Hamra GB, Richardson DB, Cardis E, Daniels RD, Gillies M, O'Hagan JA, Haylock R, Laurier D, Leuraud K, Moissonnier M, Schubauer-Berigan M, Thierry-Chef I, Kesminiene A. 2016. The International Nuclear Workers Study (INWORKS). Int. J. Epidemiol. 45: 693-699.

Howe GR, Chiarelli AM, Lindsay JP. 1988. Components and modifiers of the healthy worker effect: evidence from three occupational cohorts and implications for industrial compensation. Am. J. Epidemiol. 128: 1364-1375.

Hsu W-L., Preston DL, Soda M, Sugiyama H, Funamoto S, Kodama K, Kimura A, Kamada N, Dohy H, Tomonaga M, Iwanaga M, Miyazaki Y, Cullings HM, Suyama A, Ozasa K, Shore RE, Mabuchi K. 2013. The incidence of leukaemia, lymphoma and multiple myeloma among atomic bomb survivors:1950-2001. Radiat. Res. 179: 361-382.

IARC. 2012a. IARC monographs on the evaluation of carcinogenic risks to humans; v100E. Radiation. Lyon: International Agency for Research on Cancer Press.

IARC. 2012b. IARC monographs on the evaluation of carcinogenic risks to humans; v100F. Chemical agents and related occupations. Lyon: International Agency for Research on Cancer Press.

Laurent O, Metz-Flamant C, Rogel A, Hubert D, Riedel A, Garcier Y, Laurier D. 2010. Relationship between occupational exposure to ionizing radiation and mortality at the French electricity company, period1961-2003. Int. Arch. Occup. Environ. Health 83: 935-944. 
Laurier D, Richardson DB, Cardis E, Daniels RD, Gillies M, O'Hagan JA, Hamra GB, Haylock R, Leuraud K, Moissonnier M, Schubauer-Berigan M, Thierry-Chef I, Kesminiene A. 2017. The International Nuclear Workers Study (INWORKS): a collaborative epidemiological study to improve knowledge about health effects of protracted low dose exposure. Radiat. Prot. Dosimetry. 173: 21-25.

Leuraud K, Richardson DB, Cardis E, Daniels RD, Gillies M, O'Hagan JA, Hamra GB, Haylock R, Laurier D, Moissonnier M, Schubauer-Berigan M, Thierry-Chef I, Kesminiene A. 2015. Ionizing radiation and leukemia and lymphoma: findings from an international cohort study of radiation-monitored workers (INWORKS). Lancet Haematol. 2: e276-e281.

Little MP, Azizova TV, Bazyka D, Bouffler SD, Cardis E, Chekin S, Chumak VV, Cucinotta FA, de Vathaire F, Hall P, Harrison JD, Hildebrandt G, Ivanov V, Kashcheev VV, Klymenko SV, Kreuzer M, Laurent O, Ozasa K, Schneider T, Tapio S, Taylor AM, Tzoulaki I, Vandoolaeghe WL, Wakeford R, Zablotska LB, Zhang W, Lipshultz SE. 2012. Systematic review and meta-analysis of circulatory disease from exposure to low-level ionizing radiation and estimates of potential population mortality risks. Environ. Health Perspect. 120: 1503-1511.

Merzenich H, Hammer GP, Tröltzsch K, Ruecker K, Buncke J, Fehringer F, Blettner M. 2014. Mortality risk in a historical cohort of nuclear power plant workers in Germany: results from a second follow-up. Radiat. Environ. Biophys. 53: 405-416.

Metz-Flamant C, Bonaventure A, Milliat F, Tirmarche M, Laurier D, Bernier M-O. 2009. Low doses of ionizing radiation and risk of cardiovascular disease: a review of epidemiological studies. Rev. Epidemiol. Sante Publique 57: 347-359.

Metz-Flamant C, Guseva Canu I, Laurier D. 2011a. Malignant pleural mesothelioma risk among nuclear workers. A review. J. Radiol. Prot. 31: 9-23.

Metz-Flamant C, Samson E, Caër-Lorho S, Acker A, Laurier D. 2011b. Solid cancer mortality associated with chronic external radiation exposure at the French Atomic Energy Commission and Nuclear Fuel Company. Radiat. Res. 176: 115-127.

Metz-Flamant C, Samson E, Caër-Lorho S, Acker A, Laurier D. 2012. Leukemia risk associated with chronic external exposure to ionizing radiation in a French cohort of nuclear workers. Radiat. Res. 178: 489-498.

Metz-Flamant C, Laurent O, Samson E, Caër-Lorho S, Acker A, Hubert D, Richardson DB, Laurier D. 2013. Mortality associated with chronic external radiation exposure in the French combined cohort of nuclear workers. Occup. Environ. Med. 70: 630-638.

Montanaro F, Bray F, Gennaro V, Merler E, Tyczynski JE, Parkin DM, and the ENCR working group. 2003. Pleural mesothelioma incidence in Europe: evidence of some deceleration in the increasing trends. Cancer Causes Control 14: 791-803.

Muirhead CR, O'Hagan JA, Haylock RGE, Phillipson MA, Willcock T, Berridge GLC, Zhang W. 2009. Mortality and cancer incidence following occupational radiation exposure: third analysis of the National Registry for Radiation Workers. Br. J. Cancer 100: 206212

NRC. 2006. Health risks from exposure to low levels of ionizing radiation. BEIR VII Phase 2, National research council committee to assess health risks from exposure to low levels of ionizing radiation. Washington D.C.: The National Academies Press.

Ozasa K, Shimizu Y, Suyama A, Kasagi F, Soda M, Grant EJ, Sakata R, Sugiyama H, Kodama K. 2012. Studies of the mortality of atomic bomb survivors, report 14, 1950-2003: an overview of cancer and non cancer diseases. Radiat. Res. 177: 229-243.
Preston D, Lubin J, Pierce D, McConney M. 1993. Epicure user's guide. Seattle W.A.: Hirosoft International Corporation.

Richardson DB, Wing S. 2007. Leukemia mortality among workers at the Savannah River Site. Am. J. Epidemiol. 166: 1015-1022.

Richardson DB, Wing S, Wolf S. 2007. Mortality among workers at the Savannah River site. Am. J. Ind. Med. 50: 881-891.

Richardson DB, Laurier D, Schubauer-Berigan MK, Tchetgen ET, Cole SR. 2014. Assessment and indirect adjustment for confounding by smoking in cohort studies using relative hazards models. Am. J. Epidemiol. 180: 933-940.

Richardson DB, Cardis E, Daniels RD, Gillies M, O'Hagan JA, Hamra GB, Haylock R, Laurier D, Leuraud K, Moissonnier M, Schubauer-Berigan M, Thierry-Chef I, Kesminiene A. 2015. Risk of cancer from exposure to ionizing radiation: a retrospective cohort study of workers in France, the United Kingdom, and the United States (INWORKS). BMJ 351: h5359.

Rogel A, Carré N, Amoros E, Bonnet-Belfais M, Goldberg M, Imbernon E, Calvez T, Hill C. 2005. Mortality of workers exposed to ionizing radiation at the French National Electricity Company. Am. J. Ind. Med. 47: 72-82.

Samson E, Piot I, Zhivin S, Richardson D, Laroche P, Serond AP, Laurier D, Laurent O. 2016. Cancer and non-cancer mortality among French uranium cycle workers: the TRACY cohort. Br. Med. J. Open 6: e010316.

Schubauer-Berigan MK, Daniels RD, Fleming DA, Markey AM, Couch JR, Ahrenholz SH, Burphy JS, Anderson JL, Tseng C-Y. 2007. Risk of chronic myeloid and acute leukemia mortality after exposure to ionizing radiation among workers at four U.S. nuclear weapons facilities and a nuclear naval shipyard. Radiat. Res. 167: $222-232$.

Schubauer-Berigan MK, Daniels RD, Bertke SJ, Tseng C-Y., Richardson DB. 2015. Cancer mortality through 2005 among a pooled cohort of U.S. nuclear workers exposed to external ionizing radiation. Radiat. Res. 183: 620-631.

Telle-Lamberton M, Samson E, Caër S, Bergot D, Bard D, Bermann F, Gelas JM, Giraud JM, Hubert P, Metz-Flamant C, Néron MO, Quesne B, Tirmarche M, Hill C. 2007. External radiation exposure and mortality in a cohort of French nuclear workers. Occup. Environ. Med. 64: 694-700.

Thierry-Chef I, Marshall M, Fix JJ, Bermann F, Gilbert ES, Hacker C, Heinmiller B, Murray W, Pearce MS, Utterback D, Bernar K, Deboodt P, Eklof M, Griciene B, Holan K, Hyvonen H, Kerekes A, Lee M-C., Moser M, Pernicka F, Cardis E. 2007. The 15-country collaborative study of cancer risk among radiation workers in the nuclear industry: study of errors in dosimetry. Radiat. Res. 167: 380-395.

Thierry-Chef I, Richardson DB, Daniels RD, Gillies M, Hamra GB, Haylock R, Kesminiene A, Laurier D, Leuraud K, Moissonnier M, O'Hagan J, Schubauer-Berigan MK, Cardis E, on behalf of the INWORKS consortium. 2015. Updated and expanded external dosimetry conversion factors for workers in the nuclear industries in France, the UK and the US: methods for organ dose estimates for use in the International Nuclear Workers Study (INWORKS). Radiat. Res. 183: 632-642.

Tossavainen A. 2004. Global use of asbestos and the incidence of mesothelioma. Int. J. Occup. Environ. Health 10: 22-25.

Tucker MA. 2009. Melanoma epidemiology. Hematol. Oncol. Clin. N. Am. 23, 383-395, vii.

UNSCEAR. 2008. United Nations Scientific Committee on the Effets of Atomic Radiation 2006 report. Annex A. Epidemiological studies of radiation and cancer. New York: United Nations.

Vrijheid M, Cardis E, Ashmore P, Auvinen A, Bae J-M., Engels H, Gilbert E, Gulis G, Habib RR, Howe G, Kurtinaitis J, Malker H, 
Muirhead CR, Richardson DB, Rodriguez-Artalejo F, Rogel A, Schubauer-Berigan M, Tardy H, Telle-Lamberton M, Usel M, Veress K. 2007a. Mortality from diseases other than cancer following low doses of ionizing radiation: results from the 15country study of nuclear industry workers. Int. J. Epidemiol. 36: 1126-1135.

Vrijheid M, Cardis E, Blettner M, Gilbert E, Hakama M, Hill C, Howe G, Kaldor J, Muirhead CR, Schubauer-Berigan M, Yoshimura T, Ahn Y-O., Ashmore P, Auvinen A, Bae J-M., Engels H, Gulis G, Habib RR, Hosoda Y, Kurtinaitis J, Malker H, Moser M, Rodriguez-Artalejo F, Rogel A, Tardy H, Telle-Lamberton M, Turai I, Usel M, Veress K. 2007b. The 15-country collaborative study of cancer risk among radiation workers in the nuclear industry: design, epidemiological methods and descriptive results. Radiat. Res. 167: 361-379.
WHO. 1968. International classification of diseases. Manual of the international statistical classification of diseases, injuries, and causes of death. Based on the recommendations of the Eighth Revision Conference (1965) and adopted by the nineteenth World Health Assembly. Vol. 1. Geneva: World Health Organization.

WHO. 1977.International classification of diseases. Manual of the international statistical classification of diseases, injuries, and causes of death. Based on the recommendations of the Ninth Revision Conference (1965) and adopted by the twentyninth World Health Assembly, Vol. 1. Geneva: World Health Organization.

WHO. 2005. ICD-10: International statistical classification of diseases and related health problems: Tenth revision. Geneva: World Health Organization. Available from: http://www.who.int/ classifications/icd/icdonlineversions/en/.

Cite this article as: Leuraud K, Fournier L, Samson E, Caër-Lorho S, Laurier D. 2017. Mortality in the French cohort of nuclear workers. Radioprotection 52(3): 199-210 